\title{
Comparison of Immediate Effect of Plantar Fascia Release by Roller Massager and Transverse Friction Massage on Hamstring Flexibility in Desk Job Workers
}

Mansi Gala *1, Parag Kulkarni ${ }^{2}$, Ajay Kumar ${ }^{3}$.

${ }^{* 1}$ Masters of Musculoskeletal physiotherapy, Department of Musculoskeletal, DPO's NETT College of Physiotherapy, Mumbai, Maharashtra, India.

${ }^{2}$ Masters of Musculoskeletal physiotherapy, Associate Professor, Department of Musculoskeletal, DPO's NETT College of Physiotherapy, Mumbai, Maharashtra, India.

${ }^{3}$ Masters of Musculoskeletal physiotherapy, Principal of DPO's NETT College of Physiotherapy, Mumbai, Maharashtra, India.

\section{ABSTRACT}

Background: Desk job workers with prolonged sitting have postural imbalances and the overused muscles experience an increase in tension in one part of the body which causes excessive tension in other parts of the body due to continuity of the fascia. This fascial anatomy trains can cause stress not only on the muscle but all the structures that are surrounded by the fascia leading to dysfunction and pain.

Purpose of the study: The purpose of this study is to compare the acute effects of different techniques like selfmyofascial release and transverse friction massage on flexibility in healthy adults for effective treatment and efficient working.

Results: Main Findings- Hamstring flexibility of the desk job workers tested via Active Knee Extension Test and $\checkmark$ Sit and Reach test both pre and post of both the groups A and B showed significant difference $p<0.001$ tested by Wilcoxon Sign Rank Test. Group statistics done with Man Whitney Test showed that there is no significant difference between AKET ( $P=0.3030)$ whereas there is significant difference between $V$ SRT between the two groups $(P=0.030)$ suggesting larger variations in the group mean or any other unknown causes.

Conclusions: This study concludes that Self Myofascial Release therapy and Transverse Friction Massage therapy both are effective in improving hamstring flexibility in desk job workers when worked on the plantar fascia via the anatomy trains. Self myofascial release therapy showed better results than the transverse friction massage therapy both statistically and clinically.

Potential Implications: Thus, these methods can be used as an effective adjunct for many rehabilitation programs for speedy recovery.

KEY WORDS: Desk Job Workers, Hamstring Flexibility, Plantar Fascia, Self Myofascial Release, Transverse Friction Massage.

Address for correspondence: Dr. Mansi Gala, Masters of Musculoskeletal physiotherapy, Department of Musculoskeletal, DPO's NETT College of Physiotherapy, Mumbai, Maharashtra, India. E-Mail: mansigala8@gmail.com
Access this Article online
Journal Information

\section{Quick Response code}

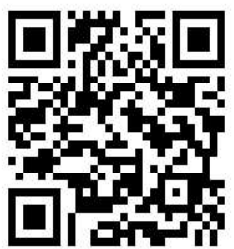

DOI: $10.16965 /$ ijpr.2021.157
International Journal of Physiotherapy and Research ISSN (E) 2321-1822 | ISSN (P) 2321-8975

https://www.ijmhr.org/ijpr.html

DOI-Prefix: https://dx.doi.org/10.16965/ijpr

\section{Article Information}

Received: 13 Jun 2021

Peer Review: 14 Jun 2021

Revised: 12 Jul 2021
Accepted: 03 Aug 2021

Published (O): 11 Aug 2021

Published (P): 11 Aug 2021
INTRODUCTION

Muscle flexibility is defined as the ability of a muscle to lengthen, allowing one or more than one joint in series to move through the range of motion. Loss of muscle flexibility is defined as the decrease in the ability of the muscle to 
deform resulting in decreased range of motion about a joint [1]. Mobility and flexibility of soft tissues that surround a joint like muscles, ligaments, fascia and other connective tissues are also necessary for normal range of motion [2]. Limited flexibility has been shown to predispose an individual to several musculoskeletal disorders and affects efficient functioning and activities of daily living [3-6].

Hamstring tightness is a very common condition found both in symptomatic and asymptomatic individuals [7]. There are different causes for hamstrings to go into tightness like genetic, acute or chronic injuries and adaptations [8].

An individual sitting all day such as a desk worker has adaptive changes taking place that can shorten their hamstrings. Prolonged sitting causes posterior pelvic tilt which causes the hamstring to go into the shortened position. Extended sitting durations and loading the muscles with large amount of forces increases the risk of injury. A sedentary lifestyle adds to making an individual prone to various problems like tightness, decreased length, ranges, and thereby decreasing flexibility which hampers the activities of daily living. Complete contraction and stretching rarely occurs and thus hamstrings are not put through their full physiologic state of contraction. Due to this reason, two joint muscles like hamstrings are commonly injured $[9,10]$. Hence poor hamstring flexibility has been associated with lower back and lower extremity issues. It is also responsible for postural and other back problems due to mal-alignment and dysfunctions caused by the inflexibility.

Flexibility may be affected by a number of reasons; one of them is fascial restrictions. Fascia is a continuous connective tissue that surrounds muscles, nerves, blood vessels and connects structures of the body. Fascia can be restricted due to injury, disease, inactivity, or inflammation. These restrictions may decrease flexibility, strength, endurance, and can lead to high amounts of physical pain [11]. Plantar fascia acts as static and dynamic stabilizer of the longitudinal arch of the foot and acts as a dynamic shock absorber [12]. It is connected via the posterior kinetic chain of the superficial backline fascial meridian with the fascias of gastrocnemius, hamstring, and erector spinae up to the scalp. Myers 2014 said that the connective tissue fascia and the underlying muscle can influence each other and if tightness prevails, any one or both of them can be the causative factor. Hence it is important to look into all the aspects for optimum flexibility of an individual for overall well being and physical fitness [13].

There are many techniques which releases the tightness and improves flexibility like static stretches, dynamic stretches, proprioceptive neuromuscular facilitation, transverse friction massage, cross-sectional massage, and myofascial release therapy with aids like foam roller or roller massager.

Foam roller can be smooth or multi-levelled of different densities, sizes and lengths. While roller massager includes equipment's like roller bar, tennis ball, lacrosse ball, etc. The exerted pressure of the foam rollers stimulates the Golgi tendon unit and decreases muscle tension. ${ }^{[14]}$ Many studies stated that foam rolling or roller massager tools have demonstrated multiple positive therapeutic effects like vascular plasticity and soft tissue restoration on performance and recovery by enhancing joint range of motion and decreasing muscle soreness [15]. Self myofascial release (SMR) by tennis ball to the plantar surface of the foot is widely used to increase flexibility and range of movement further along the posterior muscles of a proposed "anatomy train". Grieve et al suggested that an immediate clinical benefit of SMR on the flexibility of the hamstrings and lumbar spine was indicated via their study.

Massage was used for the purpose of health in the early years and more recently has been used in the management and prevention of sport injuries by adding it in a warm-up protocol to help increase acute flexibility. However, the benefits and mechanisms of massage are not well known [16]. Massage is thought to relax muscle, enhance joint flexibility by reducing the passive tension of antagonistic muscles. Crosman et al found that a single massage of the hamstring muscle 
group increased the passive range of motion in hip joints [17].

The deep friction massage, a type of massage is defined as a mechanical stimulation of the superficial tissues over a small area by means of rhythmically applied deep pressure and stretching (Kayseret al., 2005). A to and fro deep tissue massage helps to release the muscle tension, ensures proper circulation of blood and oxygen, removes muscle toxins and leads to scar deformation. It concentrates on specific areas, leading to soreness before and after the massage, yet the results are definite [18]. Many studies have shown acute positive effect on flexibility, pain and range of motion with short duration deep transverse massage across the muscle fibres along with conventional therapy. While it's isolated efficacy has not been established much with some contradictory studies [19].

There are other studies stating otherwise, while a study from JMSCR Sept 2014, Compares Myofascial Release Technique and Deep Transverse Friction Massage on Pain, Range of Motion and Functional Ability in subjects with chronic bicipital tendonitis which states that both the techniques are equally effective in reducing pain, improving ROM and functional ability evaluated by NPS, Goniometry, DASH respectively [20].

Hence there are conflicting evidences which make us intrigued to find out about the immediate effects of SMR and TFM on flexibility.

\section{METHODS}

It was a Comparative study design performed in a Metropolitan city held for 12 months in 60 Desk job workers with decreased hamstring flexibility collected by purposive sampling method.

Sample size was determined by the estimated prevalence of hamstring tightness in desk job workers aged between 30 to 50 years which was 96\% given by Pradip B, 2018.

Approval of the ethical committee and Head of the institution was obtained prior to commencing the study.

Patients fulfilling the selection criteria and willing to give written informed consent form were included in the study.
Demographic data was collected from them. The subjects were divided into two groups, Group A or Group B. Allocation was be done by lottery method.

Group A - Self Myofascial Release Therapy Group- Roller massager with tennis ball in standing on plantar fascia for 30 seconds, 3sets with 10 seconds rest interval. [21 22 23]

Group B - Transverse Friction Massage GroupTransverse friction massage in prone on plantar fascia for 30 seconds, 3sets with 10 seconds rest interval.[24 25 26]

Recording of Active Knee Extension Test (AKET) [27-31] and V Sit and Reach test (V-SRT) [32 33 34] for functional outcome before initiation of treatment \& immediately after intervention was done.

The data was analyzed using the statistical package for social science (SPSS) software version 20.0.

Data was tested for normality using the Shapiro Wilk Test. Non-Parametric tests were used to test data not passing normality.

The Intra-group statistical comparison of distribution of variables is tested using Wilcoxon signed rank test for the Nonparametric data.

The Inter-group statistical comparison of variables is done using Mann Whitney $U$ test for Non-parametric data.

In the entire study, the $p$ value less than 0.05 are considered to be statistically significant.

Pre - Post Within the Groups: Group A and B, Both pre and post values of AKET and V SRT.

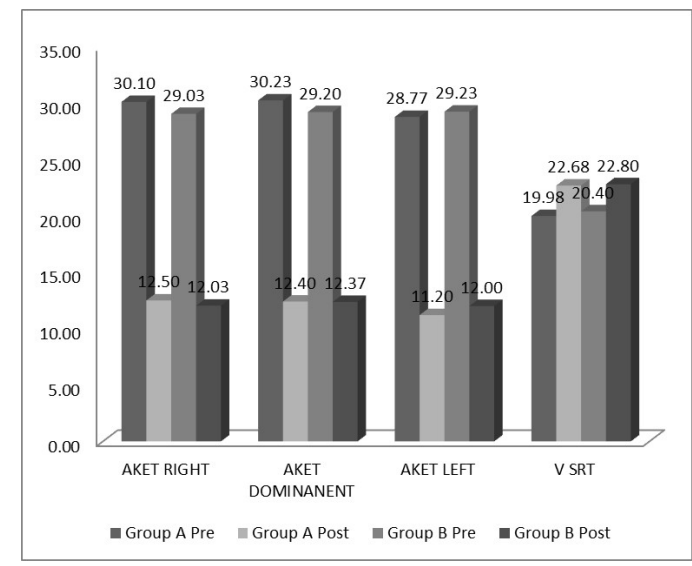

Between The Groups: Mann Whitney U Test was applied to compare data not normally distributed between the two groups. It is seen 
that there is no significant difference between AKET ( $P=0.3030)$ whereas there is significant difference between $\mathrm{V}$ SRT between the two groups $(P=0.030)$.

\begin{tabular}{cccccc}
\hline \multicolumn{6}{c}{ Group Statistics } \\
\hline \multicolumn{2}{c}{ Group } & Mean & $\begin{array}{c}\text { Std. } \\
\text { Deviation }\end{array}$ & $\begin{array}{c}\text { Man } \\
\text { Whitney }\end{array}$ & P Value \\
\hline $\begin{array}{c}\text { AKET } \\
\text { Difference }\end{array}$ & Group A & 17.83 & 3.67 & 381 & 0.303 \\
$\begin{array}{c}\text { V SRT } \\
\text { Difference }\end{array}$ & Group A & 16.83 & 4.28 & & \\
\hline
\end{tabular}

Percentage Difference: The percentage reduction in Active Knee Extension Test (AKET) in Group $A$ is more. For $V$ Sit and Reach Test ( $V$ SRT) the percentage increase in Group $A$ is more. Hence overall Group A is better.

\begin{tabular}{lcccccc}
\hline & \multicolumn{2}{c}{ Group A } & \multicolumn{2}{c}{ Group B } & \multicolumn{2}{c}{ Percentage reduction } \\
\hline & Pre & Post & Pre & Post & Group A & Group B \\
\hline Aket Right & 30.1 & 12.5 & 29.03 & 12.03 & 58.47 & 55.11 \\
Aket Dominant & 30.23 & 12.4 & 29.2 & 12.37 & 58.71 & 57.63 \\
Aket Left & 28.77 & 11.2 & 29.23 & 12 & 61.07 & 58.94 \\
V Srt & 19.98 & 22.68 & 20.4 & 22.8 & -14.15 & -11.76 \\
\hline
\end{tabular}

\section{RESULTS AND DISCUSSION}

In the present study, comparison between acute effects of self myofascial release therapy and transverse friction massage therapy on the plantar surface of the foot on hamstring flexibility is based on the hypothesis that an increase in muscle tension in one part of the body causes excessive tension in other parts of the body due to continuity of the fascia. This continuity of the fascia can cause stress not only on the muscle but all the structures that are surrounded by the fascia [35].

The comparison between pre and post AKET and V-SRT results for Group A and Group B by applying Wilcoxon test showed all the $P$ values less than 0.05 giving significant difference.

The comparison for AKET and V SRT differences between two groups $A$ and $B$ shows that there is no significant difference between AKET $(P=0.3030)$ whereas there is significant difference between $V$ SRT between the two groups $(P=0.030)$. The possible causes for this might be the small sample size or larger variations in the group mean or any other unknown causes.

Comparing the two interventions it is seen that the percentage reduction in Active Knee
Extension Test (AKET) and percentage increase in V Sit and Reach Test (V SRT) for Group A is more than that of Group $B$, thereby showing that Group A has more significant improvement both statistically and clinically than Group B.

According to Schleip et al. under normative conditions, fascia and connective tissues tend to move with minimal restrictions. However, injuries resulting from physical trauma, repetitive strain, and inflammation are thought to decrease fascial tissue length and elasticity, resulting in fascial restriction. Myofascial Release therapy is a good adjunct for many treatment protocols. Self-myofascial release (SMR) has been adapted to allow regular and frequent applications, without a therapist's intervention to return the fascial tissue to its normative length by collagen reorganization via softening, lengthening and realigning mechanisms (Sullivan et al 2013). It relates the individual to use their own body mass to exert pressure on the soft tissue as they roll over the dense foam roller (FR) (Macdonald et al 2013) or a tennis ball on the plantar aspect of the foot (Myers 2014).

Application of myofascial techniques can lead to local as well as general body relaxation, improved circulation and a decrease in myofascial tone, which may explain the findings of the present study. The findings of the present study can also be explained by the mechanical force transmission via connective tissue. In support of this theory, Carvalhais et al have shown that fascial structures function to transfer strain to neighbouring skeletal muscles with Kwangsun Doa et al showing similar results in their study- acute effects of self myofascial release using a foam roller on plantar fascia on hamstring and lumbar spine superficial back line flexibility. Also Joshi DG in 2018 showed significant improvements on hamstring flexibility while working on the remote areas of the body.

The deep friction massage is a rhythmic deep mechanical stimulation of small superficial tissue area to release the muscle tension, break scar tissue, remove muscle toxins, and improve circulation of blood and oxygen which had been affected by any dysfunction. 
In 2016, Begovic et al studied the neuromotor effects of transverse friction massage over Quadriceps femoris tendon in 14 healthy subjects where TFM was found to increase the time corresponding to EC coupling influencing on changing the neuro-motor driving mechanism possibly via afferent pathways and therefore decreasing the active muscle stiffness $^{[36]}$ while Boora $M$ et al, 2016 gave a finding of significant increase in knee extension ROM with only 30 seconds of deep friction musculotendinous massage in small circular motion of hamstring 3 times a day for one week which increases muscle-tendon compliance, along with increases in skin and muscle temperatures leading to augmented blood flow to the area by mobilizing and elongating shortened or adhered connective tissue.

Studies done by Rittu SB and Routroy $S$ compared both the techniques of MFR and DFTM on chronic plantar fasciitis and chronic bicipital tendonitis respectively concluding that both the techniques are effective in reducing pain, improving ROM and functional ability. Along with many other conflicting evidences, such studies strongly support the present study and increase its strength as an evidence for the use of such different techniques as adjuncts in many treatment protocols for effective and efficient rehabilitation and recovery.

\section{CONCLUSION}

This study concludes that Self Myofascial Release therapy and Transverse Friction Massage therapy both are effective in improving hamstring flexibility in male desk job workers when acted on the plantar fascia via the anatomy trains. Self myofascial release therapy showed better results than the transverse friction massage therapy both statistically and clinically.

Potential implications- A similar study with larger sample size or longer duration can be performed. A similar study can be done on any other muscle length considering the myofascial chains of the body. The techniques can be used as an effective adjunct therapy to enhance the rehabilitation progress.

\section{ABBREVIATIONS}

SMR/MFR-Self Myofascial Release/ Myofascial Release

DTFM/TFM- Deep Transverse Friction Massage/ Transverse Friction Massage

AKET - Active Knee Extension Test

VSRT- V- Sit and Reach Test

\section{ACKNOWLEDGEMENTS}

I am thankful to all the subjects who participated and gave their valuable time to this study. I am grateful to Dr. Parag Kulkarni and Dr. Ajay Kumar for their constant guidance and knowledge throughout the research. I acknowledge all our colleagues to help us with their support and advice and help throughout the study.

\section{Conflicts of interest: None}

\section{REFERENCES}

[1]. Garrett Jr WE, Califf JC, Bassett FH. Histochemical correlates of hamstring injuries. The American journal of sports medicine. 1984 Mar;12(2):98-103.

[2]. Kisner C, Colby LA, Borstad J. Therapeutic exercise: Foundations and techniques. Fa Davis; 2017 Oct 18.

[3]. Davis DS, Ashby PE, McCale KL, McQuain JA, Wine JM. The effectiveness of 3stretching techniques on hamstring flexibility using consistent stretching parameters. The journal of strength \& conditioning research. 2005 Feb 1;19(1):27-32.

[4]. Halbertsma JP, Mulder I, Göeken LN, Eisma WH. Repeated passive stretching: acute effect on the passive muscle moment and extensibility of short hamstrings. Archives of physical medicine and rehabilitation. 1999 Apr 1;80(4):407-14.

[5]. Halbertsma JP, van Bolhuis Al, Göeken LN. Sport stretching: effect on passive muscle stiffness of short hamstrings. Archives of physical medicine and rehabilitation. 1996 Jul 1;77(7):688-92.

[6]. Hartig DE, Henderson JM. Increasing hamstring flexibility decreases lower extremity overuse injuries in military basic trainees. The American journal of sports medicine. 1999 Mar;27(2):173-6.

[7]. Decoster LC, Cleland J, Altieri C, Russell P. The effects of hamstring stretching on range of motion: a systematic literature review. Journal of Orthopaedic \& Sports Physical Therapy. 2005 Jun;35(6):377-87.

[8]. Schuback B, Hooper J, Salisbury L. A comparison of a self-stretch incorporating proprioceptive neuromuscular facilitation components and a therapist-applied PNF-technique on hamstring flexibility. Physiotherapy. 2004 Sep 1;90(3):151-7.

[9]. Shiwani NR, Keerthi R, Neha SR. Comparison of muscle energy technique and post isometric relaxation on Iliopsoas tightness to improve flexibility in healthy young individuals. International Journal of Applied Research. 2017;3(3):16-21. 
[10]. Gajdosik R, Lusin G. Hamstring muscle tightness: reliability of an active-knee-extension test. Physical therapy. 1983 Jul 1;63(7):1085-8.

[11]. Sullivan KM, Silvey DB, Button DC, Behm DG. Roller massager application to the hamstrings increases sit and reach range of motion within five to ten seconds without performance impairments. International journal of sports physical therapy. 2013 Jun;8(3):228.

[12]. Rasal TC, Jeswani K. The effect of Cyriax (Transverse frictional massage) on pain and function in patients with plantar fasciitis randomized controlled trial study. IJAR. 2018;4(5):27-35.

[13]. Wilke J, Krause F, Vogt L, Banzer W. What is evidencebased about myofascial chains: a systematic review. Archives of physical medicine and rehabilitation. 2016 Mar 1;97(3):454-61.

[14]. Junker DH, Stöggl TL. The foam roll as a tool to improve hamstring flexibility. The Journal of Strength \& Conditioning Research. 2015 Dec1;29(12):3480-5.

[15]. Cheatham SW, Kolber MJ, Cain M, Lee M. The effects of self myofascial release using a foam roll or roller massager on joint range of motion, muscle recovery, and performance: a systematic review. International journal of sports physical therapy. 2015 Nov;10(6):827.

[16]. Jourkesh, M. The effect of massage on performance of the sit and reach test in adolescent soccer players. Medicina Dello Sport 60: 151- 155, 2007.

[17]. Barlow A, Clarke R, Johnson N, Seabourne B, Thomas $D$, Gal J. Effect of massage of the hamstring muscle group on performance of the sit and reach test. British journal of sports medicine. 2004 Jun 1;38(3):349-51.

[18]. Rittu SB. A Comparative study on the Effectiveness of Myofascial Release and Deep Friction Massage in the Management of Foot Function and Flexibility among Chronic Plantar Fasciitis Patients (Doctoral dissertation, RVS College of Physiotherapy, Coimbatore).

[19]. Joseph MF, Taft K, Moskwa M, Denegar CR. Deep friction massage to treat tendinopathy: a systematic review of a classic treatment in the face of a new paradigm of understanding. Journal of sport rehabilitation. 2012 Nov 1;21(4):343-53.

[20]. Routroy S, Patra P. Comparison of Myofascial Release Technique and Deep Transverse Friction Massage on Pain, Range of Motion and Functional Ability in Subjects with Chronic Bicipital Tendonitis: A Comparative Study.

[21]. Vigotsky AD, Lehman GJ, Contreras B, Beardsley C, Chung B, Feser EH. Acute effects of anterior thigh foam rolling on hip angle, knee angle, and rectus femoris length in the modified Thomas test. PeerJ. 2015 Sep 24; 3:e1281.

[22]. Halperin I, Aboodarda SJ, Button DC, Andersen LL, Behm DG. Roller massager improves range of motion of plantar flexor muscles without subsequent decreases in force parameters. International journal of sports physical therapy. 2014 Feb; 9(1):92.

[23]. Monteiro ER, Škarabot J, Vigotsky AD, Brown AF, Gomes TM, da Silva Novaes J. Acute effects of different self massage volumes on the $\mathrm{FMS}^{\mathrm{TM}}$ overhead deep squat performance. International journal of sports physical therapy. 2017 Feb;12(1):94.
[24]. Huang SY, Di Santo M, Wadden KP, Cappa DF, Alkanani $T$, Behm DG. Short-duration massage at the hamstrings musculotendinous junction induces greater range of motion. The Journal of Strength \& Conditioning Research. 2010 Jul 1;24(7):1917-24

[25]. Boora M, Sharma S. Study on Effectiveness of Static Stretching and Massage on Hamstring Flexibility in Normal Adults. IOSR Journal of Sports and Physical Education, Volume 3, Issue 3 (May. - Jun. 2016), PP 01-05

[26].Fernández-de-las-Peñas C, Alonso-Blanco C, FernándezCarnero J, Miangolarra-Page JC. The immediate effect of ischemic compression technique and transverse friction massage on tenderness of active and latent myofascial trigger points: a pilot study. Journal of Bodywork and Movement therapies. 2006 Jan 1; 10(1):3-9.

[27]. Hamid MS, Ali MR, Yusof A. Interrater and intrarater reliability of the active knee extension (AKE) test among healthy adults. Journal of physical therapy science. 2013;25(8):957-61

[28]. Norris CM, Matthews M. Inter-tester reliability of a self-monitored active knee extension test. Journal of bodywork and movement therapies. 2005 Oct 1; 9(4):256-9.

[29]. Davis DS, Quinn RO, Whiteman CT, Williams JD, Young $\mathrm{CR}$. Concurrent validity of four clinical tests used to measure hamstring flexibility. The Journal of Strength \& Conditioning Research. 2008 Mar 1; 22(2):583-8.

[30]. Yýldýrým Mp, Tuna F, Kabayel DD, Süt N. The Cut-off Values for the Diagnosis of Hamstring Shortness and Related Factors. Balkan medical journal. 2018 Sep; 35(5):388.

[31]. Webright WG, Randolph BJ, Perrin DH. Comparison of nonballistic active knee extension in neural slump position and static stretch techniques on hamstring flexibility. Journal of Orthopaedic \& Sports Physical Therapy. 1997 Jul;26(1):7-13

[32]. Cuberek R, Machová I, Lipenská M. Reliability of V sitand-reach test used for flexibility self-assessment in females. Acta Gymnica. 2013 Dec 18;43(1):35-9

[33]. López-Miñarro PA, Sáinz de Baranda P, Rodríguez-García $\mathrm{PL}$, Yuste JL. Comparison between sit-and-reach test and $\mathrm{V}$ sit-and-reach test in young adults. Gazzetta Medica Italiana. 2008;167(4):135-42

[34]. V sit reach test. www.topendsports.com

[35]. Schleip R, Findley TW, Chaitow L, Huijing P. Fascia: the tensional network of the human body-e-book: the science and clinical applications in manual and movement therapy. Churchill Livingstone;Elsevier: 2013. p. 131

[36]. Begovic H, Zhou GQ, Schuster S, Zheng YP. The neuromotor effects of transverse friction massage. Manual therapy. 2016 Dec 1;26:70-6

How to cite this article: Mansi Gala, Parag Kulkarni, Ajay Kumar. Comparison of Immediate Effect of Plantar Fascia Release by Roller Massager and Transverse Friction Massage on Hamstring Flexibility in Desk Job Workers. Int J Physiother Res 2021;9(4):3954-3959. DOI: 10.16965/ ijpr.2021.157 